\title{
A estética sonora no documentário Quebradeiras
}

\author{
José Francisco Serafim \& Raquel Salama Martins*
}

\author{
Quebradeiras (Brasil, 2010, 71 min.) \\ Direção: Evaldo Mocarzel \\ Roteiro: Evaldo Mocarzel e Marcelo Moraes \\ Produção: Leonardo Mecchi \\ Fotografia: Gustavo Habda \\ Trilha Sonora: Marcus Siqueira, Thiago Cury \\ Montagem: Marcelo Moraes \\ Edição de Som: Miriam Biderman, Ricardo Reis e Ana Chiarini \\ Estúdio: Raiz Produções \\ Distribuidora: Raiz Distribuidora
}

\section{Entre o documentário etnográfico e o cinema direto}

O filme Quebradeiras (2010), de Evaldo Mocarzel, é identificado como um documentário etnográfico, financiado pelo Etnodoc, um edital de apoio à produção de filmes antropológicos sobre patrimônio cultural imaterial ${ }^{1}$. De fato, Quebradeiras trata da cultura de um oficio tradicional, das mulheres quebradeiras de coco, mas o faz por meio de "uma via mais nova do documentário etnográfico", privilegiando a descrição, detendo-se no "peso do sensível" (France, 2000: 21).

* José Francisco Serafim: Doutor em Antropologia Fílmica pela Université Paris Ouest Nanterre (França), professor da Faculdade de Comunicação da Universidade Federal da Bahia (UFBA). Pesquisador do Programa de Pós-Graduação em Comunicação e Cultura Contemporâneas da UFBA. 40170-115. Salvador (BA), Brasil.

E-mail: josefserafim@ufba.br

Raquel Salama Martins: Mestranda pelo Programa de Pós-Graduação em Comunicação e Cultura Contemporâneas, da Faculdade de Comunicação da Universidade Federal da Bahia. Bolsista CNPQ. 40130-000. Salvador (BA), Brasil.

E-mail: raquelsalam@gmail.com

1. Oriundo de projeto mais amplo, intitulado "Sensibilização e orientação para salvaguarda do patrimônio cultural imaterial", o Etnodoc foi criado a partir de um grupo de trabalho composto por especialistas do Centro Nacional de Folclore e Cultura Popular e do Departamento de Patrimônio Imaterial, do Instituto do Patrimônio Histórico e Artístico Nacional (Iphan), autarquia federal vinculada ao Ministério da Cultura do Brasil.

Doc On-line, n. 23, março de 2018, www.doc.ubi.pt, pp. 244-254. 
Com efeito, os sons ambientais, que são aqueles que surgem do ambiente natural ou humano em que a ação das quebradeiras ocorre, constituem o que se poderia chamar de paisagem sonora do documentário. Eles são gravados cuidadosamente e manipulados no conjunto de edição com a atenção que é normalmente reservada para as imagens. Desta forma, o diretor Mocarzel faz, ao menos do ponto de vista da banda sonora, o que o antropólogo cineasta Paul Henley considera necessário para melhorar a qualidade dos filmes etnográficos: "espessa a descrição etnográfica sobre a qual o filme se baseia", aumenta a "compreensão dos espectadores e a experiência indireta do assunto apresentado no filme" e amplia "os modos através dos quais o cineasta pode propor uma interpretação do significado desse assunto" (Henley, 2007: 03).

Podemos observar também em Quebradeiras algumas características do cinema direto. O filme em si, no seu mecanismo narrativo, abre mão do recurso expressivo da entrevista, o que não necessariamente significa que antes o diretor tenha se eximido de conversar com as pessoas. Inspirado nas obras do cinema direto, Evaldo Mocarzel se utiliza da montagem para produzir sentido.

Outra característica é o modo observacional de filmar. De fato, a forma como Evaldo Mocarzel retrata as quebradeiras, em especial na roda do samba de coco, nos remete muito à compreensão que Jean-Louis Comolli nos traz do cinema direto. De acordo com este autor, este tipo de cinema coloca a câmera para dançar com os corpos de tal modo que desenvolve "uma intimidade rítmica que nunca fora acessível, a não ser por meio da imaginação, da poesia ou do romance" (Comolli, 2006: 110).

Esta aproximação com o cinema direto coloca Quebradeiras na esteira de uma nova tendência do documentário brasileiro contemporâneo, em que a voz humana, enquanto discurso, vai cedendo cada vez mais espaço para outros elementos da banda sonora, como a música e os ruídos. Apostando na observação como forma de garimpar imagens e sons, Evaldo Mocarzel se aproxima de um grupo de cineastas brasileiros do Estado de Minas Gerais que vêm experimentando com o som, a exemplo de Marília Rocha (Aboio, 2005) e Marcos Pimentel (Sopro, 2013). Nestes filmes, como bem definiu Cláudia Mesquita, temos em comum:

(...) de um lado, a resistência à abordagem verbal de temas e assuntos prévios, e uma espécie de investimento na presença bruta e na superfície imediata do cotidiano; de outro, certa ênfase na temporalidade da experiência de pessoas e localidades, mesmo quando tratadas de modo fragmentário pela enunciação (Mesquita, 2010: 200).

Desta forma, a inscrição de Quebradeiras como documentário etnográfico não nos impede de considerá-lo dentro de um contexto mais amplo, do documentário contemporâneo, em que as fronteiras entre gêneros e subgêneros se 
borram e podemos identificar características de diferentes modos de representar o outro.

Além disso, como vimos através das reflexões de Paul Henley, a tendência em dar uma atenção maior aos sons ambientais, desde a captação até a edição, também começa a ser observada mesmo entre os documentários etnográficos. Então, independentemente de ser ou não etnográfico, o que importa aqui é a atenção dada em Quebradeiras à banda sonora, em particular aos ruídos, como elemento importante da narrativa fílmica.

\section{A estética sonora de Quebradeiras}

Nos seus 71 minutos de duração, o documentário Quebradeiras faz algo mais do que retratar a rica cultura de um grupo de mulheres da região do Bico do Papagaio, fronteira entre os Estados do Maranhão, Tocantins e Pará, que extraem das palmeiras de babaçu o fruto de seu sustento. As imagens de Gustavo Hadba, a trilha sonora minimalista de Thiago Cury e Marcus Siqueira e os ruídos da natureza e do trabalho criam uma atmosfera em torno do cotidiano dessas camponesas. Nesse universo predominantemente feminino, acompanhamos suas atividades. Após coletar e quebrar a casca do coco para extrair a castanha, elas usam a castanha para a produção de azeite, sabão e farinha, a casca do coco para produzir carvão, bem como a palha das folhas para a confecção de cestos.

Ao longo do filme, o que parece interessar o cineasta é, além das cores dos lugares e das texturas das coisas, as sonoridades do trabalho das mulheres quebradeiras. Ouvimos o farfalhar das folhas ao vento quando elas caminham na floresta em busca dos cocos; o rumor da coleta dos cocos secos; o baque dos porretes contra a casca do fruto pousado na lâmina de um machado, para a retirada da castanha branca; o rumor das águas dos regatos e o ranger das cordas da rede quando descansam no final da jornada de trabalho.

Esses sons vão sendo apresentados de forma cíclica, começando por intensidades baixas que vão subindo até atingir o ápice e depois vão diminuindo novamente. Os ruídos dos fazeres e saberes das quebradeiras de coco são colocados em primeiro plano de tal forma que deixam de ser ruídos e passam a narrar, na relação com as imagens, o cotidiano das trabalhadoras, a passagem do tempo, os ciclos de produção.

Com base na obra de Gilbert Durand, Michel Chion, Murray Schafer e Daniel Deshays, podemos compreender o som enquanto "imagem simbólica" (Durand, 1993) e identificar os diferentes "temas das paisagens sonoras" (Schafer, 1997) que são representadas nos documentários. Durand diz que a imagem simbólica "é transfiguração de uma representação concreta através 
de um sentido abstrato e parcial" (Durand, 1993:11 e 12). Na experiência cotidiana, nós fazemos essa transfiguração quando escutamos um som e atribuímos a ele um sentido abstrato. Neste caso, podemos tomá-lo como imagem simbólica.

Ao falar sobre procedimentos de análise da paisagem sonora, compreendida como qualquer campo de estudo acústico, Murray Schafer também se refere à dimensão simbólica de alguns sons. Ele propõe descobrir os aspectos significativos da paisagem sonora, "aqueles sons que são importantes por causa de sua individualidade, quantidade ou preponderância" (Schafer, 2001: 25) e identifica alguns temas: os sons fundamentais, sinais, marcas sonoras e os sons arquetípicos, que define como "misteriosos sons antigos, não raro imbuídos de oportuno simbolismo, que herdamos da alta Antiguidade ou da Pré-História" (Schafer, 2001: 26). E o que mais chama a atenção é a ressalva que ele faz em relação aos sons fundamentais, que são os sons criados pela geografia e clima, como o som da água, do vento, planícies, montanhas e animais. Para Schafer, mesmo esses sons fundamentais podem conter um significado arquetípico, ter uma presença marcante na vida das pessoas que os ouvem. É o que acontece com o som do vento passando pelos babaçuais em Quebradeiras, que aparece de forma mais saliente em quatro momentos do filme.

Daniel Deshays nos mostra como podemos organizar a paisagem sonora para, dentre sua infinita riqueza, produzir significado e sentimentos. Ele descreve duas operações básicas para a escritura do sonoro: a primeira consiste em classificar e selecionar os fenômenos que se encaixam bem na criação; a segunda consiste em criar novas formas e estruturas em ruptura com as práticas aceitas.

O filme analisado é bem rico no que se refere à representação das paisagens sonoras através dessas operações da escritura do sonoro que Daniel Deshays nos descreve. Em Quebradeiras, o que parece se destacar é aquela segunda operação da escritura do sonoro, da qual fala Deshays, em que novas formas e novas estruturas são criadas em ruptura com os padrões. Os ruídos cotidianos, com toda a sua forma compassada pela qual se apresentam, são colocados em primeiro plano de tal forma que por vezes se transformam em música, e essa percepção musical do som ambiente também se dá através da justaposição dos planos visuais e sonoros das mulheres quebrando o coco e das rodas de danças. Ora é o plano sonoro das quebradeiras que invade o plano visual das rodas, ora é o plano sonoro das rodas que invade o plano visual das quebradeiras, uma forma de mostrar o quanto a manifestação artística se inspira na sonoridade local. 
No documentário, para que possamos sentir a musicalidade do som ambiente das mulheres quebradeiras, essa ruptura também se dá no plano visual, em articulação com os planos sonoros. Nos primeiros 12 minutos do documentário, temos mais da metade dos planos apresentando-se como plano detalhe, em que o som resultante da ação também se apresenta de forma aproximada, destacada dos demais sons.

O uso desse tipo de plano se intensifica num primeiro momento, quando as mulheres estão quebrando o coco. Logo no início, já vemos os cocos secos no chão, de perto, através de um plano-detalhe, seguido de um outro plano-detalhe da mão da quebradeira segurando um pedaço de pau, e ainda o da outra mão segurando o coco babaçu sobre a lâmina do machado. Depois de vermos o movimento das mãos e dos braços quebrando o coco babaçu através de uma câmera baixa, segue-se um primeiríssimo plano do rosto da quebradeira, onde continuamos a ouvir o som da batida do porrete sobre o coco, com o som do vento e da mata ao fundo.

Novamente, uma sequência de planos detalhes intercala a visão sobre o gesto de quebrar o coco com as expressões do rosto, das mãos, cotovelo, o olhar sobre o cesto, ombro, voltando sempre às mãos, até voltar ao plano geral do babaçual, da cena em que a quebradeira se lava no rio, e depois vai, num primeiríssimo plano, banhar-se num banheiro improvisado, onde segue-se mais uma sequência de planos-detalhe do banho, revelando, através do ombro, o movimento de jogar a água sobre o rosto, até chegar ao movimento de pentear o cabelo, ainda molhado. A sequência de planos-detalhe só acaba com um plano de conjunto, seguido de um plano da quebradeira na rede, intervalos nos quais já não escutamos mais nem a batida do coco, nem o jorrar da água, apenas o som do vento, da mata, revelando o momento do descanso.

Esse uso intensivo de planos-detalhe, acompanhado de toda a sua sonoridade, ajuda a representar as sensações de estar no meio do babaçual, quebrando o coco ao lado da quebradeira, ou mesmo no lugar dela. Além de criar um ritmo, com planos curtos, nos permite adentrar o universo feminino, através de um ponto de vista de quem está dentro do quadro. É como se estivéssemos lá, vendo e escutando de perto cada batida, cada movimento do corpo, cada gesto, cada olhar.

Em outros momentos, a câmera nos coloca no lugar da mata, do babaçual, como se a árvore, tão venerada pelas mulheres quebradeiras de coco, fosse um outro personagem do filme. Quando uma nova quebradeira está chegando no babaçual, estamos no ponto de vista da palmeira de babaçu, que vê a quebradeira chegar e coletar seus frutos caídos e já maduros, prontos para serem extraídos. 
Em outro trecho do documentário, é a mulher que contempla as palmeiras. Após fazer todo o seu serviço do campo e da casa, ela se posta à janela e olha para o céu, onde está o topo das palmeiras babaçus, como a agradecer pelo dia de trabalho, pelo alimento. De acordo com a pesquisadora Viviane Barbosa, as quebradeiras de coco veem as palmeiras de babaçu como mulheres, fazendo uma associação entre as mães quebradeiras e as palmeiras mães de acordo com o universo de práticas e representações do mundo do trabalho e dos significados atribuídos à natureza:

Em diversos contextos maranhenses, as palmeiras têm sido pensadas principalmente em sua função feminino de ser mãe. Há uma inter-relação entre ser mãe e exercer as funções de cuidado, de sustento, de nutrição e as agroextrativistas têm geralmente acionado discursos em que as palmeiras se apresentam nessa condição. (Barbosa, 2013: 126).

Num outro momento que conota essa relação intimista entre as quebradeiras e as palmeiras, vemos uma senhora quebradeira espremendo o leite do coco babaçu batido, e em seguida avistamos uma mãe amamentando seu bebê. São planos de momentos diferentes justapostos com a clara intensão de ilustrar a visão que as quebradeiras têm das palmeiras babaçu, como mães, já que elas fornecem inclusive o leite, que estava sendo extraído pela senhora.

O documentário Quebradeiras começa com um primeiro plano, onde só nos é dado ver o interior da casa, ainda assim através de uma cortina, por onde percebemos a silhueta da mulher a sair para o trabalho. Neste mesmo plano, escutamos a sonoridade do entorno da casa da camponesa, o carcarejar das galinhas, o canto dos pássaros. O próximo plano visual já é um local mais afastado da casa, pois já não ouvimos mais as galinhas, somente os pássaros e o balançar das folhas pelo vento.

Nesse sentido, os sons que compões a ambiência do lugar são percebidos pelo espectador sem que ele possa ver por completo os elementos que compõe o ambiente, propiciando a ele a oportunidade de uma escuta mais atenta, próximo àquilo que Michel Chion chama de escuta reduzida:

Uma escuta que trata das qualidades e das formas específicas do som, independentemente da sua causa e do seu sentido; e que considera o som - verbal, instrumental, anedótico ou qualquer outro - como objeto de observação, em vez de o atravessar, visando através dele outra coisa. (Chion, 2008: 29-30).

É através dessa escuta que conseguimos perceber a musicalidade dos sons produzidos pelas mulheres quebradeiras de coco, uma diversidade de sons resultado da forma como são produzidos, com variados ritmos, e dos materiais e gestos que os produzem, com alta ou baixa intensidade. Cada etapa do processo de produção das quebradeiras é demarcada com a culminância nas rodas de dança ou nas rezas cantadas. Na primeira parte, temos a princípio um som 
de fraca intensidade, da coleta dos cocos secos no chão, que passam para uma intensidade mais forte com a quebra do coco, passando pelo banho no rio e no banheiro improvisado, até culminar com o descanso, na rede, em que ouvimos apenas os sons da natureza.

$\mathrm{Na}$ cena seguinte, temos novamente o som da coleta do coco, tendo como ponto alto a lavagem do arroz, passando pelo som do varrer da casa até culminar novamente no som da natureza, que é o momento em que a mulher contempla a paisagem na janela. Nestes momentos de descanso, já não temos mais uma escuta, e sim um simples ouvir, como neste momento em que a mulher se posta na janela a contemplar o babaçual, imersa em um som ambiente, harmônico e uniforme.

Após esses dois ciclos de trabalho, compostos de quatro etapas (caminhada, coleta, extração e limpeza; caminhada, coleta, alimentação e limpeza), intercalados por momentos de descanso, avistamos a primeira roda de dança. Como observado anteriormente, o uso intenso de planos-detalhe coloca o espectador dentro da roda do samba de coco, ${ }^{2}$ assim como fez o espectador caminhar junto com a quebradeira e sentar ao lado dela, percebendo cada movimento, cada gesto, e suas sonoridades.

Após alguns minutos, já estamos como que adentrando a roda de samba. Do plano detalhe da cintura das quebradeiras, segue-se o plano detalhe da boca do tocador cantando o coco, voltando às cinturas sendo tocadas pelas mãos dos sambadores, seguido pelos pés "pisando o coco", e assim se sucede, até culminar num plano de conjunto, onde vemos todos os brincantes no terreiro, e novamente voltamos ao plano-detalhe da boca do cantador, das cinturas das sambadeiras, pés, mãos tocando o ganzá, novamente os pés, numa sequência tão vertiginosa de planos-detalhe que de repente vemos também as mãos da mulher quebrando o coco na lâmina do machado.

Desta vez, o som da batida do porrete de pau sobre o coco se confunde com o som da batida do tambor, e o som da abertura manual do coco se confunde com o som do ganzá. Estes sons do trabalho das mulheres quebradeiras, que aparecem em meio à roda do samba de coco, podem ser compreendidos como sons internos, tal como define Michel Chion, mais especificamente como sons internos subjetivos, por remeter a uma memória:

O som interno é som que, embora situado no presente da ação, corresponde ao interior físico e mental de um personagem. Estes incluem sons fisiológicos de respiração, gemidos ou batimentos cardíacos, todos os quais podem

2. O samba de coco teve origem no canto dos tiradores de coco e só depois se transformou em ritmo dançado. O coco apresenta uma coreografia básica, que pode variar conforme o lugar: "os participantes formam filas ou rodas onde executam o sapateado característico, respondem o coco, trocam umbigadas entre si e com os pares vizinhos e batem palmas marcando o ritmo" (Gaspar, 2017). 
ser denominados sons objetivos-internos. Também nessa categoria de sons internos estão vozes mentais, memórias, e assim por diante, que chamo de sons subjetivos-internos. (Chion, 1994: 76).

A inserção de imagens e sons do trabalho das quebradeiras em meio à roda de samba é uma forma de expressar a similaridade entre essas sonoridades. Este tipo de manipulação da faixa sonora é, para Paul Henley, o mais discutível e também mais interessante, pois reflete uma interpretação do diretor, como se fosse um comentário:

(...) realizada não apenas para enriquecer a descrição do ambiente acústico ou para cumprir certos requisitos funcionais dentro da estrutura do filme (...), mas sim oferecer algum tipo de comentário sobre a ação do filme, dando um certo significado a uma cena particular e/ou provocando uma variedade particular de sentimentos no espectador" (Henley, 2007: 05).

Quanto mais se intensificam os planos-detalhe, maior é a sensação de estarmos dentro da roda. É neste momento, já no final da roda do samba de coco, que a musicalidade do trabalho das mulheres quebradeiras se revela com maior força, através dessa associação entre planos de curta duração, em que as mãos tocando os instrumentos na roda de samba se confundem com as mãos da mulher quebrando o coco.

No segundo ciclo de produção, quando o coco babaçu é torrado na panela e depois passa por processo de cozimento, o que se destaca é a percepção da "temporalidade da experiência" das mulheres quebradeiras de coco (Mesquita, 2010: 200). No documentário, todo esse processo dura dois minutos e dezoito segundos. Parece pouco, mas para um filme de 71 minutos, é suficiente para sentirmos tanto o tempo, quanto o ritmo do trabalho, caracterizado por uma certa musicalidade, dado o compasso de quatro por quatro ${ }^{3}$ no mexer da castanha com o pau, por exemplo.

Mais uma vez, o ciclo de trabalho se encerra com um período de descanso. Desta vez, é o babaçual que vemos descansar, através de um belo plano das palmeiras que parecem formar um grande rosto de uma mulher. E novamente percebemos o tempo transcorrer. O tempo da noite, a sonoridade da noite, as cores da noite. A mata sem a inquietude do vento, sem pássaros. Somente as aves noturnas, como a coruja, além das cigarras e dos grilos. A lua cheia a iluminar o céu, de um azul escuro até o anoitecer. No amanhecer, o contraste da luz do sol e da sonoridade, mais intensa, mais pujante de vida, com as folhas das palmeiras novamente se inquietando com o vento.

3. Rui Motta, no livro Bateria em todos os níveis, observa que os compassos determinam a cadência rítmica da música e são formados por tempos. O compasso de quatro por quatro seria, portanto, uma cadência de quatro tempos. 
Em câmera baixa, vemos uma senhora quebradeira, em contraluz, em pé num balanço entre as palmeiras babaçu, sob o som de um reisado, que é mostrado logo em seguida. O efeito é muito bonito, pois gera um sentimento de valorização da mulher quebradeira de coco. A câmera baixa a coloca numa posição de superioridade, e sobre a imagem temos um som de festejo. Além disso, ela está ao lado de duas grandes palmeiras, que a sustentam no balanço, assim como sustentam de fato as mulheres quebradeiras de coco, ao doar seus frutos para o trabalho dessa comunidade extrativista.

O terceiro ciclo de trabalho é a produção da farinha do coco babaçu. Desta vez, a sonoridade é mais ruidosa, devido ao uso da máquina, e talvez por esse motivo já não temos mais a recorrência constante ao plano-detalhe, que só aparece quando o coco está sendo descascado ou quando a farinha já está sendo ensacada, gerando um ruído mais leve e agradável. Temos uma recorrência maior ao plano geral e principalmente ao plano de conjunto, com uma exploração da luz e das cores do trabalho das mulheres, bem como o primeiríssimo plano, expondo suas expressões faciais. $\mathrm{O}$ terceiro ciclo de trabalho se encerra mais uma vez com o "silêncio" do babaçual, onde ouvimos apenas o farfalhar das folhas das palmeiras. A este momento de descanso segue-se mais um momento de festividade, onde as mulheres estão devidamente vestidas para o samba de coco, com suas saias rodadas.

A música do samba fala de fogo: A cidade pegou fogo, fogo na cidade...é fogo, é fogo, fogo na cidade. O tema do samba tem alguma relação com as imagens que se seguem, que são justamente sobre a atividade de produção do carvão a partir da queima das cascas de coco babaçu. A justaposição do plano do samba com o plano da fumaça da queima das cascas não é gratuita, pois as cantigas do samba costumam ser as cantigas de trabalho das mulheres quebradeiras de coco. Os primeiros planos que aparecem são como que planos-detalhe da fumaça, e só depois é que aparecem planos mais abrangentes, quando percebemos que se trata da atividade de produção de carvão. No final, já não ouvimos mais nem o samba, sem o fogo, somente o vento e o som do carvão ainda em brasa, seguido do plano das palmeiras, onde novamente só ouvimos o farfalhar das folhas do babaçual ao vento.

O último ciclo de produção, que no filme dura no máximo 30 segundos, é justamente sobre o artesanato da palha da palmeira babaçu, que tanto ouvimos durante todo o documentário. O filme acaba com o momento de finalização do reisado, que é a oração do pai nosso cantada, um momento de agradecimento. O som da prece continua, mas o que se segue é a imagem de uma das mulheres quebradeiras indo banhar-se no rio. Esse plano final sintetiza as diversas 
referências ao feminino que são feitas ao longo do documentário: a mulher, a água e a mata ao redor.

\section{Considerações finais}

Ao longo deste texto, tentamos demonstrar, através da análise do documentário Quebradeiras, de Evaldo Mocarzel, como os sons podem ser captados e manipulados no documentário para construir a paisagem sonora de um lugar, tecendo como que uma segunda camada de representação, "tornando mais espessa a descrição etnográfica sobre a qual o filme se baseia" (Henley, 2007). Para a antropóloga Viviane Vedana, os sons são também imagens da cultura porque a representam:

“(...) tanto no que se refere às musicalidades, orações e canções, quanto às narrativas e memórias das pessoas expressas pela voz e pela fala, aos ruídos da vida em comunidade que emanam das técnicas, tecnologias, utensílios e todo tipo de produção humana, aos sons ambientais ou da natureza expressos pelo correr das águas de um rio, pelas rajadas de vento, pelo canto dos pássaros, etc." (Vedana, 2011: 31).

Vimos também como, através da justaposição dos planos visuais e sonoros das mulheres quebrando o coco e das rodas de danças, o cineasta consegue apresentar um comentário sobre a musicalidade do trabalho das quebradeiras de coco. Diante da evidência de uma relação que não se dá de forma direta entre som e imagem, devemos refletir sobre o lugar das sonoridades na composição dos filmes documentários. Para além do valor de acréscimo, observamos que existe uma narrativa sonora paralela à narrativa visual, na qual os sons têm uma relativa autonomia para contar a história.

\section{Referências bibliográficas}

Aumont, J. \& Marie, M. (2009). A análise do filme. Lisboa: Edições Texto \& Grafia.

Barbosa, V. de O. (2013). Mulheres do Babaçu: gênero, maternalismo e movimentos sociais no Maranhão. Niterói: Tese de Doutorado, Universidade Federal Fluminense.

Chion, M. (2008). A audiovisão, som e imagem no cinema. Lisboa: Texto \& Grafia.

Chion, M. (1994). Audio-vision: sound on screen. New York: Columbia University Press.

Comolli, J.-L. (2008). Ver e poder: a inocência perdida - cinema, televisão, ficção, documentário. Belo Horizonte: Editora UFMG. 
Durand, G. (1993). A imaginação simbólica. Lisboa: Edições 70.

Deshays, D. (2006). Pour une écriture du son. Paris: Klincksieck.

France, C. de (2000). Do filme etnográfico à antropologia filmica. Campinas, SP: Editora Unicamp.

Gaspar, L. (s.d.). Coco (dança). Recife: Fundação Joaquim Nabuco. Disponível em: http://basilio.fundaj.gov.br/pesquisaescolar/. Acesso em 14 de dezembro de 2017.

Heider, K. G. (2006). Ethnographic film. Austin: University of Texas Press.

Henley, P. (2007). Seeing, hearing, feeling: sound and the despotism of the eye in 'visual' anthropology. Visual anthropology review, 23 (1).

MaCdougall, D. (1998). Transcultural cinema. New Jersey: Princeton University Press.

Mesquita, C. (2010). A superfície do cotidiano: uma aproximação a acidente e uma encruzilhada aprazível. In C. Migliorin (org.), Ensaios no real: o documentário brasileiro hoje. Rio de Janeiro: Beco do Azougue.

Motta, R. C. (2013). Bateria em todos os níveis. São Paulo: Irmãos Vitale.

Piault, M.-H. (2004). Antropologia e cinema. Catálogo II Mostra Internacional do filme etnográfico. Rio de Janeiro: Interior Produções.

Schafer, M. (1997). A afinação do mundo. São Paulo: Fundação Editora da UNESP.

Vedana, V. (2011). Diálogos entre a imagem visual e a imagem sonora: a experiência da escritura do sonoro nos documentários etnográficos. Revista Ciberlegenda: 29-42. Niterói.

\section{Filmografia}

Aboio (2005), de Marília Rocha.

Quebradeiras (2010), de Evaldo Mocarzel.

Sanã (2013), de Marcos Pimentel.

Sopro (2013), de Marcos Pimentel. 